\title{
HUBUNGAN LINGKAR LENGAN ATAS IBU HAMIL TERHADAP ANTROPOMETRI BAYI BARU LAHIR DI RUMAH SAKIT IBU DAN ANAK ANANDA KOTA MAKASSAR
}

\author{
Rizka Amalia*, Azizah Nurdin**, Jelita Inayah Sari***, Andi Irhamnia Sakinah**** \\ Fakultas Kedokteran dan Ilmu Kesehatan Universitas Islam Negeri Alauddin Makassar \\ Email: rizkaamalia2098@gmail.com
}

\begin{abstract}
The newborn's body dimensions are influenced by maternal nutritional status that can be determined by measuring mid upper arm circumference (MUAC). The aim of this study was to determine relationship between maternal MUAC and anthropometry of newborn at Ananda Women and Children Hospital Makassar. The method used in this study was analytic with cross sectional design. A total of 200 pregnant women underwent delivery at Ananda Women and Children Hospital Makassar were taken by purposive sampling method. The study data were sourced from primary data i.e. demographic data, maternal MUAC and newborn anthropometry which included weight, length, head circumference, and chest circumference that were measured immediately after birth. Data were analyzed using the Chi-Square test on the IBM SPSS 23. The results of this study showed a significant relationship between maternal MUAC with body length $(p=0,000)$, head circumference $(p=0,000)$, and chest circumference $(p=0,013)$ of newborns, but no significant relationship was found between maternal MUAC with body weight of newborns $(p=0.127)$. This study conclude that maternal MUAC influence the anthropometry of newborns on the parameters of body length, head circumference, and chest circumference.
\end{abstract}

Keywords: MUAC, anthropometry, newborn baby

\section{PENDAHULUAN}

Permasalahan gizi dan kesehatan ibu dan anak masih merupakan permasalahan kompleks baik di Indonesia maupun secara global. Data World Health Organization (WHO) menunjukkan bahwa pada tahun 2016 jumlah anak penderita stunting sebesar 155 juta, dengan 56\% berada di Asia. Kejadian Bayi Berat Lahir Rendah (BBLR) pada Bayi Baru Lahir (BBL) atau neonatus pada periode 2005-2010 sebesar 15\%. Pada tahun 2016, jumlah anak di bawah usia 5 tahun (balita) yang mengalami overweight (berat badan lebih) diperkirakan sebanyak 41 juta anak. Adapun balita yang dikategorikan wasting sebanyak 52 juta anak, dengan $69 \%$ di antaranya adalah anak yang berasal dari Asia (WHO, 2018).

Berdasarkan data Kementerian Kesehatan tahun 2015, Angka Kematian Ibu (AKI) di Indonesia adalah 346 per 100.000 kelahiran hidup, sedangkan Angka Kematian Bayi (AKB) sebesar 32 per 1000 kelahiran hidup. Adapun prevalensi kekurangan gizi (underweight) pada balita mencapai $19,5 \%$ dan prevalensi stunting (pendek dan sangat pendek) pada anak baduta (bawah dua tahun) sebesar 32,9\%. Terkait kondisi kesehatan ibu, Riskesdas 2018 menunjukkan bahwa prevalensi risiko 
Kekurangan Energi Kronis (KEK) pada wanita hamil sebesar 17,3\%. Kisaran persentase tertinggi risiko KEK ini ditemukan pada wanita hamil dalam rentang usia 15-34 tahun. Data tersebut menandakan bahwa kondisi kesehatan di Indonesia khususnya ditinjau dari aspek gizi belum dalam keadaan baik (Kemenkes RI, 2018).

Tumbuh kembang seorang anak berlangsung sangat pesat pada periode seribu hari pertama kehidupan yang dimulai sejak konsepsi hingga anak berusia dua tahun (Herlina, 2018). Status gizi ibu sejak konsepsi hingga melahirkan mempengaruhi status gizi janin yang akan dilahirkan (Harjatmo, 2017). Kerusakan yang timbul di periode ini bersifat irreversible atau tidak dapat dibenahi di fase kehidupan berikutnya serta mempengaruhi kondisi kesehatan anak hingga usia dewasa (Safaa, 2016). ${ }^{5}$

Penilaian status gizi dapat diketahui dengan antropometri. Parameter antropometri yang dapat diukur pada bayi baru lahir antara lain berat badan, panjang/tinggi badan, lingkar lengan atas, lingkar kepala, dan lingkar dada (Harjatmo, 2017). Pada ibu hamil, pengukuran status gizi lazim dilakukan dengan mengukur lingkar lengan atas (LILA). Dari LILA dapat diketahui adanya risiko menderita kurang energi kronis (KEK) pada ibu hamil atau wanita usia subur (WUS). Ambang batas hasil pengukuran LILA WUS untuk menetapkan risiko KEK di Indonesia adalah 23,5 cm (Tang, 2016).

Wanita hamil dengan status gizi rendah berisiko melahirkan bayi dengan berat badan lahir rendah (BBLR), retardasi pertumbuhan janin dalam rahim yang mungkin memiliki konsekuensi pada perkembangan bayi baru lahir, serta berefek buruk pada perkembangan sistem kekebalan tubuh bayi baru lahir (Kumar, 2018; Soetjiningsih, 2014).

Rumah Sakit Ibu dan Anak (RSIA) Ananda adalah salah satu rumah sakit ibu dan anak swasta di kota Makassar dengan jumlah persalinan yang cukup tinggi. Pada tahun 2018 tercatat sebanyak 4.906 persalinan ditolong rumah sakit ini dari total 25.911 persalinan di Kota Makassar (Dinkes Kota Makassar, 2019).

Tingginya angka kejadian BBLR dan pentingnya pemantauan status gizi pada ibu hamil terutama yang mengalami KEK membuat peneliti mengangkat topik ini sebagai bahan penelitian.

\section{METODE PENELITIAN}

Metode yang digunakan dalam penelitian ini adalah analitik dengan rancangan cross sectional. Rancangan penelitian ini digunakan untuk mengetahui hubungan variabel dependen yaitu antropometri bayi baru lahir yang meliputi berat badan, panjang badan, lingkar kepala, dan lingkar dada, dengan variabel independen yaitu lingkar lengan atas ibu hamil. Penelitian dilakukan bulan Januari 
2020 di Rumah Sakit Ibu dan Anak (RSIA) Ananda Kota Makassar. Populasi pada penelitian ini adalah seluruh ibu hamil trimester ketiga yang menjalani persalinan di RSIA Ananda Kota Makassar. Pengambilan sampel dilakukan dengan menggunakan teknik non-probability sampling yaitu purposive sampling dengan jumlah sampel sebanyak 200 yang memenuhi kriteria inklusi dan eksklusi. Adapun yang termasuk kriteria inklusi yaitu ibu hamil yang melahirkan RSIA Ananda Kota Makassar, cukup bulan, bayi lahir hidup, dan bersedia ikut dalam penelitian. Adapun kriteria eksklusi yaitu ibu dengan kehamilan ganda (gemelli), menderita penyakit infeksi, anemia berat, diabetes, hipertensi, jantung dan asma, serta ibu yang merokok dan mengonsumsi alkohol saat hamil.

Sumber data yang digunakan dalam penelitian ini adalah data primer dan data sekunder. Data primer diperoleh melalui observasi dan pengukuran langsung LILA ibu dan antropometri bayi diukur segera setelah lahir. Data sekunder diperoleh dari rekam medik Rumah Sakit Ibu dan Anak Ananda Kota Makassar.

Data yang diperoleh kemudian dianalisis menggunakan software IBM SPSS 23. Analisis hubungan antara variabel

dependen dan independen menggunakan uji Chi-Square.

\section{HASIL DAN PEMBAHASAN}

\section{Hasil Penelitian}

Karakteristik subjek penelitian dimuat dalam tabel 1. Tabel 1 menunjukkan bahwa dari total 200 responden, distribusi responden berdasarkan usia terbanyak pada kelompok usia 20 - 35 tahun sebanyak 178 orang (89\%), diikuti kelompok usia $<20$ tahun sebanyak 7 orang $(3,5 \%)$ dan kelompok usia >35 tahun sebanyak 15 orang $(7,5 \%)$. Mayoritas responden telah melalui lama pendidikan wajib 9 tahun sebanyak 190 orang (95\%), tetapi masih ada sebanyak 10 orang (5\%) yang memiliki lama pendidikan $\leq 9$ tahun.

Distribusi responden berdasarkan status kerja terbesar pada kelompok tidak bekerja yakni sebanyak 113 orang $(56,5 \%)$, sedangkan responden yang bekerja sebanyak 87 orang (43,5\%). Mayoritas responden adalah ibu primipara yakni sebanyak 112 orang (56\%), sedangkan ibu multipara sebanyak 88 orang $(44 \%)$. Berdasarkan LILA, dari total 200 ibu hamil sebagian besar dikategorikan normal (tidak KEK), yakni sebanyak 184 orang (92\%), dan sisanya ibu dengan KEK sebanyak 16 orang (8\%).

Tabel 1. Distribusi responden berdasarkan usia, lama pendidikan, status kerja, dan paritas di Rumah Sakit Ibu dan Anak Ananda Kota Makassar Tahun 2020

\section{Karakteristik responden}

\section{Frekuensi}

(n)
Persentase

(\%) 
Usia

- $<20$ tahun

- $20-35$ tahun

- > 35 tahun

Lama pendidikan

$-\leq 9$ tahun

- >9 tahun

Status kerja

- Bekerja

- Tidak Bekerja

Paritas

- Primipara

- Multipara

LILA ibu

- $\quad<23,3 \mathrm{~cm}$ (KEK)

- $\quad \geq 23,5 \mathrm{~cm}$ (tidak KEK)

\section{Sumber: Data Primer}

Distribusi antropometri bayi baru lahir dimuat dalam tabel 2. Berdasarkan berat badan, dari total 200 bayi baru lahir sebagian besar memiliki berat lahir $\geq 2500$ gram yakni sebanyak 192 bayi (96\%), sedangkan bayi BBLR (< 2500 gram) sebanyak 8 bayi (4\%). Berdasarkan panjang badan, dari total 200 bayi baru lahir, bayi dengan panjang badan lahir $\geq 48 \mathrm{~cm}$ sebanyak 163 bayi (81,5\%), sedangkan bayi dengan panjang badan $<48 \mathrm{~cm}$ sebanyak 37 bayi (18,5\%). Berdasarkan lingkar kepala dari total 200 bayi baru lahir, bayi dengan lingkar kepala normal $(32-37 \mathrm{~cm})$ sebanyak 99 bayi (49,5\%), sedangkan bayi dengan lingkar kepala $<32 \mathrm{~cm}$ sebanyak 101 bayi (50,5\%). Berdasarkan lingkar dada dari total 200 bayi baru lahir, bayi dengan lingkar dada normal $(30-35 \mathrm{~cm})$ sebanyak 187 bayi $(93,5 \%)$, sedangkan bayi dengan lingkar dada $<30 \mathrm{~cm}$ sebanyak 13 bayi $(6,5 \%)$.

Tabel 2. Distribusi antropometri bayi responden di Rumah Sakit Ibu dan Anak Ananda Kota Makassar Tahun 2020

\begin{tabular}{lcc}
\hline Antropometri bayi baru lahir & Frekuensi (n) & Persentase (\%) \\
\hline Berat badan (gram) & 8 & 4 \\
$-<2500$ & & \\
& & p-ISSN 2460-9749 \\
& & e-ISSN 2620-5890
\end{tabular}


$-\quad \geq 2500$

Panjang badan $(\mathrm{cm})$

- $<48$

- $\quad \geq 48$

Lingkar kepala $(\mathrm{cm})$

- $<32$

$-\quad \geq 32$

Lingkar dada $(\mathrm{cm})$

$-<30$

$-\quad \geq 30$

Total

200

100

Sumber: Data Primer

Tabel 3. Analisis bivariat hubungan LILA ibu dengan berat badan lahir bayi di Rumah Sakit Ibu dan Anak Ananda Kota Makassar tahun 2020

\begin{tabular}{ccccc}
\hline \multirow{2}{*}{$\begin{array}{c}\text { Antropometri bayi } \\
\text { baru lahir }\end{array}$} & \multicolumn{2}{c}{ LILA Ibu Hamil $(\mathrm{cm})$} & \multirow{2}{*}{$\begin{array}{c}\text { Total } \\
(\mathrm{n}(\%))\end{array}$} & Nilai P \\
\cline { 2 - 3 } & $<23,5(\mathrm{n}(\%))$ & $\geq 23,5(\mathrm{n}(\%))$ & & \\
\hline Berat badan (gram) & & & & \\
$-\quad<2500$ & $2(1 \%)$ & $6(3 \%)$ & $8(4 \%)$ & \\
$-\quad \geq 2500$ & $14(7 \%)$ & $178(89 \%)$ & $192(96 \%)$ & 0,127
\end{tabular}

Panjang badan $(\mathrm{cm})$

$-\quad<48$

$9(4,5 \%)$

$28(14 \%)$

$37(18,5 \%)$

0,000

$-\quad \geq 48$

$7(3,5 \%)$

$156(78 \%)$

$163(81,5 \%)$

Lingkar kepala $(\mathrm{cm})$

$-\quad<32$

$15(7,5 \%)$

$86(43 \%)$

$101(50,5 \%)$

$-\geq 32$

$1(0,5 \%)$

98(49\%)

$99(49,5 \%)$

0,000

Lingkar dada $(\mathrm{cm})$

$-\quad<30$

$4(2 \%)$

$9(4,5 \%)$

$13(6,5 \%)$

$-\quad \geq 30$

$12(6 \%)$

$175(87,5 \%)$

$187(93,5 \%)$

0,013

Total

$16(8 \%)$

184(92\%) 200(100\%)

\section{Sumber: Data Primer}

Hasil analisis bivariat hubungan kemaknaan 0,05). Diperoleh nilai $\mathrm{p}<0,05$ lingkar lengan atas ibu hamil dengan pada hubungan antara variabel LILA keempat variabel antropometri bayi baru terhadap variabel panjang badan, lingkar lahir menggunakan uji Chi-Square dengan kepala dan lingkar dada. Namun, diperoleh confidence interval $95 \%$ (derajat nilai $\mathrm{p}>0,05$ pada hubungan antara variabel 
LILA terhadap variabel berat badan. Hal ini menunjukkan bahwa terdapat hubungan bermakna secara statistik antara LILA ibu dengan panjang badan, lingkar kepala, dan lingkar dada bayi baru lahir, tetapi tidak terdapat hubungan bermakna secara statistik antara LILA ibu dengan berat badan bayi baru lahir.

\section{Pembahasan}

Lingkar lengan atas (LILA) digunakan sebagai indikator perkembangan kehamilan dan keluaran lahir. Tidak seperti berat absolut atau kenaikan berat badan selama kehamilan, LILA cukup konstan pada ibu selama kehamilan dan karenanya jika berat tidak tersedia, lingkar lengan yang diambil setiap saat selama kehamilan dapat berfungsi untuk memberikan gambaran berat badan sebelum hamil (Rani, 2017). Tidak ada perbedaan yang signifikan dalam pengukuran LILA di tiga trimester, yang menunjukkan bahwa pengukuran ini independen terhadap usia kehamilan (Okereke, 2013).

Tabel 3 menunjukan analisis hubungan LILA ibu hamil terhadap berat badan lahir bayi. Mayoritas responden memiliki lingkar lengan atas $\geq 23,5 \mathrm{~cm}$ dengan berat badan bayi lahir $\geq 2500$ gram yakni sebesar 178 responden atau $89 \%$ dari total responden keseluruhan. Berdasarkan hasil uji Chi-Square pada analisis Fisher Exact Test diperoleh nilai p sebesar 0,127 (p $>0,05)$ sehingga diketahui bahwa tidak terdapat hubungan yang signifikan antara lingkar lengan atas ibu terhadap berat badan lahir bayi.

Hasil ini ditemukan pula pada penelitian yang dilakukan oleh Liang di Makassar, yang menunjukkan bahwa tidak terdapat hubungan yang signifikan antara ukuran LILA ibu pada masa kehamilan dengan berat bayi pada saat lahir dengan nilai $\mathrm{p}=1,034$ (Liang, 2017). Hasil ini juga didukung oleh penelitian yang dilakukan oleh Winther di Nepal bahwa LILA menunjukkan efek negatif terhadap berat lahir dalam analisis regresi multivariat (koefisien korelasi -0,165). Efek LILA terhadap berat badan kecil dan tidak signifikan secara statistik dengan nilai $\mathrm{p}=$ 0,084 (Winther, 2013). Hasil ini bertolakbelakang dengan penelitian di Aceh dan India yang menunjukkan bahwa terdapat hubungan signifikan antara lingkar lengan atas ibu hamil dengan berat badan lahir bayi ( $\mathrm{p}<0,05)$ (Putri, 2015).

Ververs dkk menyimpulkan bahwa LILA adalah indikator yang paling dapat diandalkan untuk mengetahui risiko BBLR. Mereka juga menyimpulkan bahwa pengukuran lingkar lengan atas membutuhkan peralatan minimal dan telah ditemukan untuk memprediksi morbiditas dan mortalitas seakurat defisit berat badan (Ververs, 2013). Satu studi dilakukan oleh Islam di Bangladesh menunjukkan bahwa tingkat cut-off $23,5 \mathrm{~cm}$ menunjukkan sensitivitas dan spesifisitas tinggi untuk 
memprediksi berat badan lahir rendah (Islam, 2014).

Lingkar lengan atas ibu hamil sangat mempengaruhi kesempurnaan perkembangan janin selama dalam kandungannya, tetapi belum tentu semua ibu hamil yang mengalami KEK (LILA < 23,5) selalu melahirkan bayi berat lahir rendah (BBLR), karena banyak faktor yang mempengaruhi kelahiran BBLR. Hal ini karena banyak faktor lain yang mempengaruhi berat badan lahir bayi, seperti dari faktor internal ibu yaitu usia ibu hamil, jarak kehamilan dan kelahiran, paritas, kadar hemoglobin, pemeriksaan kehamilan, penyakit saat kehamilan. Faktor eksternal seperti faktor lingkungan meliputi kebersihan dan kesehatan lingkungan tempat tinggal, faktor sosial dan ekonomi meliputi jenis pekerjaan, tingkat pendidikan dan pengetahuan ibu hamil (Putri, 2015).

Pada penelitian ini tidak ditemukan hubungan bermakna antara LILA ibu dengan berat badan lahir bayi karena dipengaruhi oleh beberapa faktor. Dalam penelitian ini, jumlah sampel ibu dengan KEK berjumlah 16 orang dari total 200 sampel tapi hanya 2 di antaranya yang melahirkan bayi BBLR. Adapun beberapa faktor yang mempengaruhi berat lahir bayi yang tidak terjangkau dalam penelitian ini antara lain adalah kenaikan berat badan ibu hamil, asupan nutrisi selama kehamilan, jarak kehamilan, kadar hemoglobin, pemeriksaan kehamilan, dan juga faktor lingkungan serta sosial ekonomi responden.

Tabel 3 menunjukan analisis hubungan LILA ibu hamil terhadap panjang badan bayi. Mayoritas responden memiliki lingkar lengan atas $\geq 23,5 \mathrm{~cm}$ dengan panjang badan bayi $\geq 48 \mathrm{~cm}$ yakni sebesar 156 responden atau $78 \%$ dari total responden keseluruhan. Berdasarkan hasil uji Chi-Square pada analisis Continuity Correction diperoleh nilai $\mathrm{p}$ sebesar 0,000 $(\mathrm{p}<0,05)$ sehingga diketahui bahwa terdapat hubungan yang signifikan antara lingkar lengan atas ibu terhadap panjang badan lahir bayi.

Hasil ini sejalan dengan penelitian yang dilakukan oleh Rani di India yang menunjukkan bahwa terdapat hubungan signifikan antara LILA ibu dengan panjang badan bayi ( $\mathrm{p}$ 0,0001) (Rani, 2017). Penelitian lain yang dilakukan oleh Lamana di Palu juga mendukung hasil penelitian ini, yang menyimpulkan bahwa panjang badan bayi baru lahir berhubungan dengan tinggi badan ibu ( $\mathrm{p}<0,001)$ dan LILA ibu (dan $\mathrm{p}$ $<0,001)$ (Lamana, 2017).

Panjang badan dianggap sebagai indikator kasar dari massa tanpa lemak, yang mencerminkan pertumbuhan skeletal. Terdapat beberapa faktor yang mempengaruhi panjang badan bayi baru lahir seperti status gizi ibu sejak sebelum kehamilan, infeksi, status anemia dan kadar mikronutrien di dalam tubuh ibu hamil (Pereira, 2012). 
Ibu hamil KEK seharusnya mempunyai risiko melahirkan bayi stunting karena kejadian KEK pada trimester ketiga dapat menyebabkan penurunan suplai zat gizi dari ibu ke janin. Proses pertumbuhan yang tidak berjalan sempurna karena kurangnya suplai zat gizi dari ibu menyebabkan kecenderungan mengalami malnutrisi seperti stunting meningkat (Newman, 2009).

Hasil penelitian ini sesuai dengan teori bahwa status gizi ibu mempengaruhi status gizi bayi yang dilahirkan. Ibu hamil dengan status gizi yang baik akan memberikan pasokan nutrient yang adekuat dalam mendukung proses pertumbuhan dan perkembangan janin, termasuk pertumbuhan skeletal janin sejak dalam kandungan. Sehingga bayi yang dilahirkan dari ibu dengan status gizi baik cenderung akan melahirkan bayi dengan panjang badan normal, begitu pun sebaliknya ibu yang mengalami kekurangan nutrisi akan cenderung melahirkan bayi dengan panjang badan di bawah batas normal.

Tabel 3 menunjukan analisis hubungan LILA ibu hamil terhadap lingkar kepala bayi. Mayoritas responden memiliki lingkar lengan atas $\geq 23,5 \mathrm{~cm}$ dengan lingkar kepala bayi $32-37 \mathrm{~cm}$ yakni sebesar 98 responden atau $49 \%$ dari total responden keseluruhan. Berdasarkan hasil uji Chi-Square pada analisis Fisher Exact Test diperoleh nilai $\mathrm{p}$ sebesar $0,000(\mathrm{p}<$ 0,05) sehingga diketahui bahwa terdapat hubungan yang signifikan antara lingkar lengan atas ibu terhadap lingkar kepala lahir bayi.

Hasil ini sesuai dengan penelitian yang dilakukan oleh Nagmoti di India yang menunjukkan hasil bahwa status gizi ibu ditinjau dari IMT $(p=0,039)$ dan berat badan $(p=0,007)$ berhubungan dengan lingkar kepala bayi baru lahir (Nagmoti, 2015).

Pengukuran lingkar kepala penting dilakukan pada bayi baru lahir untuk mengetahui perkembangan saraf anak dan perkembangan otak selama dalam kandungan. Diketahui bahwa LILA ibu berhubungan dengan lingkar kepala, maka status gizi ibu yang baik akan mendukung pertumbuhan optimal sel-sel saraf janin sejak dalam kandungan.

Lingkar kepala yang mencerminkan lingkar oksipitofrontal menggambarkan pertumbuhan otak, meskipun itu bukan ukuran sensitif atau spesifik. Lingkar kepala tidak sepenuhnya berkorelasi dengan volume dan perkembangan otak. Beberapa faktor harus dipertimbangkan ketika menginterpretasikan pengukuran lingkar kepala pada neonatus. Selama minggu pascanatal pertama, lingkar kepala dapat menurun sekitar $0,5 \mathrm{~cm}$ karena kontraksi ruang cairan ekstraseluler. Jika nilai lingkar kepala di atas atau di bawah batas referensi, terdapat kemungkinan masih menggambarkan variasi normal (Pereira, 2012). 
Tabel 3 menunjukan analisis hubungan LILA terhadap lingkar dada bayi. Mayoritas responden memiliki lingkar lengan atas $\geq 23,5 \mathrm{~cm}$ dengan lingkar dada bayi $\geq 30 \mathrm{~cm}$ yakni sebesar 175 responden atau $87,5 \%$ dari total responden keseluruhan. Berdasarkan hasil uji ChiSquare pada analisis Fisher Exact Test diperoleh nilai $\mathrm{p}$ sebesar $0,013(\mathrm{p}<0,05)$ sehingga diketahui bahwa terdapat hubungan yang signifikan antara lingkar lengan atas ibu terhadap lingkar dada lahir bayi.

Penelitian yang dilakukan oleh Elshibly di Sudan menunjukkan hasil yang serupa, bahwa LILA ibu berhubungan kuat dengan lingkar dada bayi yang dilahirkan (p $<0,001$ ) (Elshibly, 2009). Penelitian yang dilakukan oleh Nagmoti di India juga menunjukkan hasil yang mendukung penelitian ini, bahwa status gizi ibu ditinjau dari IMT berhubungan dengan lingkar dada neonatus ( $\mathrm{p}=0,001)$ (Nagmoti, 2015).

Penelitian yang dilakukan oleh Azevedo di Brazil menunjukkan bahwa terdapat korelasi positif antara lingkar dada dengan berat badan, panjang badan dan lingkar kepala neonatus. Pengukuran lingkar dada rutin dilakukan sebagai alat sensitif untuk mengidentifikasi status kesehatan bayi, misalnya pada kondisi kelainan rongga toraks pada periode neonatal. Ini sering dikaitkan dengan tulang rusuk kecil, sempit, dan memanjang yang khas dari perkembangan tulang rusuk abnormal (Azevedo, 2019).

Studi yang dilakukan oleh Ndu di Nigeria menyimpulkan bahwa pengukuran lingkar dada bayi baru lahir dapat menjadi alternatif untuk mendeteksi BBLR karena pengukuran lingkar dada relatif mudah dilakukan dan menunjukkan korelasi paling baik dengan berat badan dibandingkan dengan parameter antropometri lainnya (Ndu, 2014).

LILA yang berhubungan signifikan dengan lingkar dada menunjukkan bahwa ibu dengan status gizi normal atau tanpa kekurangan energi kronik akan mampu menunjang pertumbuhan fisik janin secara optimal. Namun demikian, perlu dilakukan studi lebih lanjut untuk mengidentifikasi faktor-faktor apa saja yang dapat berkaitan dengan lingkar dada bayi baru lahir.

Korelasi secara spesifik status nutrisi ibu dengan lingkar dada, lingkar kepala dan panjang badan bayi yang dilahirkan belum banyak dibahas. Diperlukan penelitian lebih lanjut untuk menjelaskan hubungan yang tepat antara variabel ini dan melibatkan mekanisme yang mendasarinya.

\section{KESIMPULAN}

Berdasarkan hasil analisis bivariat maka dapat disimpulkan bahwa terdapat hubungan signifikan antara lingkar lengan atas ibu hamil terhadap, panjang badan lahir, lingkar kepala, dan lingkar dada bayi baru lahir, tetapi tidak terdapat hubungan 
signifikan antara lingkar lengan atas ibu hamil terhadap berat badan bayi baru lahir.

\section{DAFTAR PUSTAKA}

Azevedo IG, dkk. (2019). Chest circumference in full-term newborns: how can it be predicted? BMC Pediatrics. Vol 19: 341.

Dinkes Kota Makassar. (2019). Profil Kesehatan Kota Makassar Tahun 2018. Makassar: Dinkes Kota Makassar.

Elshibly EM, Schmalisch G. (2009). Relationship between maternal and newborn anthropometric measurements in Sudan. Pediatrics International. 51, 326-331.

Harjatmo TP, Par'i HM, Wiyono S. (2017). Bahan Ajar Gizi Penilaian Status Gizi. Jakarta: Pusat Pendidikan Sumber Daya Manusia Kesehatan Badan Pengembangan dan Pemberdayaan Sumber Daya Manusia Kesehatan, Kemenkes RI.

Herlina S. (2018). Faktor - Faktor yang Berhubungan Dengan Pertumbuhan Bayi 6-12 Bulan di Puskesmas Simpang Baru. Jurnal Endurance. 3(2): 330-336.

Islam MM. (2014). Association of maternal body mass index (BMI) and mid upper arm circumference (MUAC) and birth weight of newborn in the southwest region of Bangladesh. Int J Food Nutri Sci. 3(1):1-4.

Kemenkes RI. Riset Kesehatan Dasar 2018. (2018). Jakarta: Badan Litbangkes Kemenkes RI.

Kumar P, dkk. (2018). Screening Maternal Acute Malnutrition Using Adult Mid-Upper Arm Circumference in Resource-Poor Settings. Indian J Community Med. 43(2): 132-134. dengan Berat Badan Bayi di Rumah Sakit Umum Cut Meutia Kabupaten Aceh Utara dan Rumah Sakit Tk IV IM.07.01 Lhokseumawe Tahun 2015. Jurnal Kedokteran dan Kesehatan Malikussaleh.
Lamana A, Julia M, Dasuki D. (2017). Korelasi Tinggi Badan Ibu dengan Panjang Badan Bayi Baru Lahir di Kota Palu. Jurnal Kesehatan Reproduksi. 4 (2): 103-108.

Liang YT. (2017). Pengaruh Status Gizi Ibu Hamil Terhadap Hasil Luaran Bayi. Makasar: FK UNHAS.

Nagmoti SA, Walvekar, PR, Mallapur, MD. (2015). Association Between Body Mass Index of Mother And Anthropometry of Newborn. Int J Med Res Health Sci. 4(4):796-79.

Ndu IK, dkk. (2014). Chest and OccipitoFrontal Circumference Measurements in the Detection of Low Birth Weight Among Nigerian Newborns of Igbo Ethnicity. Italian Journal of Pediatrics. Vol. 40: 81.

Newman BM, Newman PR. (2009). Development Through Life: A Psychosocial Approach, Tenth Edition. USA: Wadsworth, Cengage Learning. [Accessed Januari, 2020]. Available from URL:

http://books.google.co.id/books.

Okereke CE, dkk. (2013). Evaluation of Some Anthropometric Indices for the Diagnosis of Obesity in Pregnancy in Nigeria: A CrossSectional Study. Afr Health Sci. 13 (4) :1034-40.

Pereira-da-Silva L, Virella D, Fusch C. (2012). Neonatal anthropometry: A tool to evaluate the nutritional status, and to predict early and late risks. In The Handbook of Anthropometry: Physical Measures of Human Form.in Health and Disease; Preedy, V.R., Ed.; Springer Science + Business Media: New York, USA, 1079-1104.

Putri AR, Muqsith A. (2015). Hubungan Lingkar Lengan Atas Ibu Hamil

Rani N, dkk. (2017). Correlation Between Maternal Mid Upper Arm Circumference and Neonatal Anthopometry. International Journal of Medical Research and Review. 5(7). 
Safaa S, dkk. (2016). Effect of Malnutrition During Pregnancy on Pregnancy Outcomes. J Nurs Care. 5 (10).

Soetjiningsih. (2014). Tumbuh Kembang Anak. Jakarta: EGC.

Tang AM, Chung M, Dong K, dkk. (2016). Determining a Global Mid-Upper Arm Circumference Cutoff to Assess Malnutrition in Pregnant Women. Washington, DC: FHI360/Food and Nutrition Technical Assistance III Project (FANTA).

Ververs MT, dkk. (2013). Which Anthropometric Indicators Identify a Pregnant Woman as Acutely Malnourished and Predict Adverse Birth Outcomes in the Humanitarian Context? PLoS Currents. 7 (5).

Winther II. (2013). Maternal Anthropometry as a Predictor of Birth Weight: A study performed at Okhaldhunga Community Hospital inrural Nepal. University of Oslo. [Accessed Januari, 2020]. Available from URL: http://www.duo.uio.no/.

World Health Organization (WHO). (2018). Maternal, Infant and Young Child Nutrition Comprehensive Implementation Plan on Maternal, Infant and Young Child Nutrition: Biennial Report. Executive Board. 142/2 